\title{
Moderators of Framing Effects on Political Attitudes: Is Source Credibility Worth Investigating?
}

\author{
Dana Raluca Buturoiu, Nicoleta CORBu ${ }^{1}$
}

\begin{abstract}
This research paper focuses on indirect (mediated) media effects. In particular, we discuss which independent variables might intervene in and moderate the impact of framing effects on public attitudes (namely political trust), both in short-term and medium-term contexts. Among these, we focus on source credibility as a possible moderator of framing effects over time. The purpose of this study was to examine if and how source credibility influences individuals' political trust. The moderator role of source credibility is analysed according to the exposure to different types of frames (repetitive or competitive) at different moments (one week or one month). By means of a framing experiment $(N=769)$ on political topics, we argue that media frames could influence political trust: Source credibility has a marginal influence, which suggests that, with stronger stimulus material (video, as opposed to written press articles), the source could play an important role in the willingness of people to trust political figures in general. Thus, we might argue that the media play a significant role not only in offering information about politics and politicians, but also in altering people's perceptions about them. On the other hand, time seems to matter, since framing effects are more powerful after competitive media exposures. This study proposes new theoretical insights into framing effects, in the sense that classical theories should be revisited in various cultural or political contexts
\end{abstract}

Keywords: Framing Effects; Moderators; Source Credibility; Repetitive Frames; Competitive Frames

\section{Setting the big picture - towards a "naturalistic" approach}

Often seen as one of the main sources of political information, media tend to go further. They influence people's perceptions, opinions and attitudes and,

\footnotetext{
${ }^{1}$ Both authors work at the College of Communication and Public Relations, National University of Political Studies and Public Administration, Bucharest, Romania. Contact: raluca.buturoiu@comunicare.ro; nicoleta.corbu@comunicare.ro.
} 
sometimes, they might cause significant changes. The way in which media choose to present (i.e., to frame) an event or a situation is reflected in the way audiences perceive it. More specifically, media can play a role in influencing people's perceptions of politics and politicians. Thus, indirectly, media can have a "word" to say in both electoral and other political-related contexts.

Based on a communication perspective, this article aims at investigating if and how media frames influence young people's perceptions of politics and trust in politicians. There are two main motivations that drive this research. Firstly, if media prove to be successful in modifying young people's attitudes towards politics and politicians, we might conclude that media have a deeper role in influencing political behaviour in general. Secondly, if media are successful in telling people how to think about politics and politicians, we might argue for the real-life effects of news framing.

Recently, existing findings from news framing areas have been questioned in terms of their real-life value. There is a tradition among framing scholars to rely "on the mere assumption" (Lecheler and de Vreese 2013: 148) that their findings can be used to predict social or political phenomena from real-life. Therefore, more and more framing research scholars are trying to find arguments in order to support the relevance of their work in real-life contexts (e.g., Entman, Matthes and Pellicano 2009; Lecheler and de Vreese 2011; Matthes 2012; Matthes and Schemer 2012; Schemer, Wirth and Matthes 2012). But what do adaptability and relevance to real-life mean? How can framing research studies provide valid and reliable conclusions?

The answers to these questions are highly provocative and should be seen as the next necessary development for the future study of framing effects (de Vreese 2004; Druckman and Nelson 2003). Our main aim was to answer these questions, in an attempt to reach more reality-oriented conclusions. Thus, we suggest that only by considering the significance of the type of media exposure, the source characteristics, and the longevity of framing effects can we draw convincing conclusions about the importance of framing studies and "refute criticism of the value of framing theory" (Lecheler and de Vreese 2013: 148). In other words, we want to suggest a more "naturalistic" approach towards framing effects, which not only includes the investigation of the type of media message and its source, but also emphasizes the role of time.

Alongside its reality-oriented nature, this study aims at filling a gap identified in framing effects studies. Although rare, there are some studies which focus on the impact of either the type of exposure (repetitive or competitive messages) (Cappella and Jamieson 1997; Chong and Druckman 2007c; Lee, McLeod and Shah 2008; Nabi 2003; Price and Tewksbury 1997) or the source characteristics on framing effects on audiences (e.g., Kohring and Matthes 2007; Nah and Chung 2011; Smith, De Houwer and Nosek 2012; Xu 2013). There are also some studies which consider the importance of the durations of framing effects (Chong and 
Druckman 2010; Lecheler and de Vreese 2011, 2013). However, we did not find any research study which focused on these three issues at the same time. Thus, we wanted to broaden the study of framing effects on political attitudes (especially political trust) to a more integrative-oriented perspective. Rephrased, we suggest that we cannot reach valuable real-based conclusions about framing effects on audiences' perceptions of politics and political trust unless we consider the interplay of media exposure, the source of the message, and the effective duration of media effects.

This paper focuses on three possible moderators of framing effects on political attitudes: the credibility of the message source, the type of media exposure, and the passage of time. As far as the credibility of the message source is concerned, we will focus on both recent and classical approaches. More specifically, we will analyse the role played by both high and low credibility sources in moderating framing effects on political attitudes. The second possible moderator of framing effects is the type of media exposure - repetitive or competitive. We will explore if and how the repetition of a message or, by contrast, the alternation between messages could moderate framing effects on political attitudes. The third moderator of framing effects is the passage of time; we will analyse the moderating role of time in either enhancing or limiting framing effects on political attitudes.

\section{Moderators of framing effects}

Media frames have been shown to affect audiences' opinions, attitudes, and behaviours in various circumstances (Carter 2013; de Vreese, Boomgaarden and Semetko 2011; Iyengar 1990, 1991; Miller and Krosnick 2000). There is recent evidence that research studies have moved their interest from simply identifying and analysing framing effects on public attitudes to revealing individual and contextual factors that influence the impact of framing effects (e.g., de Vreese 2004; de Vreese, Boomgaarden and Semetko 2011; Lecheler, de Vreese and Slothuus 2009; Matthes 2008; Matthes and Schemer 2012). It has been found that framing effects can be enhanced, diminished, or even blocked through the influence of some factors, suggestively called moderators.

As Lecheler, de Vreese and Slothuus (2009: 401) suggest, the main question is what exactly limits or intensifies framing effects. To give an answer, the literature shows that there are sufficient variables that are expected to moderate framing effects, either at the level of the individual or at a contextual level. Thus, among individual-level moderators, both theoretical and empirical studies include variables such as political knowledge or sophistication (Adriaansen, van Praag and de Vreese 2012; Nelson, Oxley and Clawson 1997), individual predispositions and values (e.g., Hansen 2007; Schemer et al. 2012), and emotional or affective involvement (e.g., Marcus, Neuman and MacKuen 2000; Marcus et al. 2005). On 
the other hand, among moderators that might have an impact due to the context, studies include variables such as source characteristics (Druckman 2001; Tormala and Petty 2004), interpersonal communication (e.g., Druckman and Nelson 2003), and competitive exposure (e.g., Chong and Druckman 2007a, 2007b). Thus, according to the literature, we might conclude that the study of media framing effects would be incomplete if we do not consider some independent variables as moderators of framing effects.

At the level of the individual, a significant number of studies have dealt with the question of how political knowledge has an impact on the magnitude and processing of a media message (Lecheler de Vreese and Slothuus 2009: 401-402). These studies mainly follow two trends: One group of researchers considers that "less knowledgeable" individuals are more influenced by framing effects (e.g., Schuck and de Vreese 2006), whereas the other group believes the contrary (e.g., Nelson, Oxley and Clawson 1997). But, as Druckman and Nelson (2003: 731732) suggest, measuring political knowledge can be confusing and can result in misaddressed conclusions. As the authors point out, it is not "the knowledge per se at work", but the availability of relevant information and pre-existing considerations that moderate framing effects. Thus, the main conclusion here is that individual-level moderators are worth studying, but the investigation of framing effects in situations more "akin to daily life" (Lecheler, de Vreese and Slothuus 2009: 402) cannot be performed without considering the context.

Moving further to the contextual level, researchers advocate that the investigation of framing effects could be carried out by providing a frame with some characteristics that are found in natural contexts. While some studies suggest that these characteristics imply different sources or different types of messages (i.e., some repetitive, others competitive in nature), others argue in favour of the influence of social contacts (Hartman and Weber 2009). There are two main things that should be taken into account. First, since hardly any media message comes without a "specific messenger", we expect that framing effects on public attitudes are limited by source credibility (Druckman 2001). Second, since real media scenarios are dynamic and imply exposure to consonant (i.e., repetitive frames) and dissonant (i.e., competitive frames) messages, we expect that framing effects vary according to the type of media exposure. For these reasons, this study examines both source credibility and the type of exposure as the two main moderators of framing effects on public attitudes. The role of time is also analysed in order to reach a more complete picture of news media influence on people's political attitudes, since studies show that the passage of time can either multiply or diminish framing effects.

In this context, the general research questions that account for all these types of influence (source credibility, type of exposure, and time between exposures) are the following: 
RQ1: How can source credibility function as a moderator of framing effects?

RQ2: How can the type of media exposure function as a moderator of framing effects?

RQ3: How can the passage of time influence framing effects?

\section{a. Source credibility}

Although important, we will not focus on media credibility itself in this part of the paper. Instead, in line with the sleeper effect theory, we will discuss the role played by message source credibility as a moderator of framing effects on political attitudes, namely political trust. Initially discussed by Hovland and his colleagues (e.g., Hovland, Janis and Kelley 1953; Hovland and Weiss 1951), the main idea of the sleeper effect theory is that the credibility of the message source might influence the perceived impact of that message among audiences. Specifically, messages coming from high credibility sources have a greater impact at the beginning, while those coming from low credibility sources could have a greater impact as time passes. An explanation might be that people tend to forget the message source more rapidly than the message content. In other words, in the competition between message source and message content, the latter s more likely to win out.

The attention devoted to the interplay of sender-receiver characteristics, as well as to the role of the message source within the entire process of communication, is not a limited to very recent research (see, for example, Zaller 1992). Surprisingly, although source characteristics in general and source credibility in particular have great potential in moderating framing effects on opinions, attitudes and behaviours, they have not been the topic of a large number of studies.

There are some socio-psychological approaches that argue in favour of the influence of source characteristics on attitude formation and change (e.g., Briñol and Petty 2004; Kruglanski et al. 2004). Theoretical studies suggest that source characteristics could influence the process of attitude change for different reasons and to different degrees. This is the context in which some scholars suggest that varying levels of influence of the message source could be explained by considering three main qualitatively different dimensions of source characteristics. These dimensions are the powver or the authority of the source, source credibility, and the degree of identification with the source (Hartman and Weber 2009: 539-540). As the authors suggest, according to the first dimension, a source seen as powerful leads to compliance, and individuals that are under the influence of a perceived powerful source tend to maintain a given belief as long as they feel the presence of the authority figure. The second dimension refers to the idea that a source seen as credible leads to conformism and that individuals that are under 
the influence of a perceived credible source are more susceptible to persuasion. Conformity and the greater capacity to be persuaded arise mainly from the perceived expertise of the source. Accordingly, in a framing experiment, Druckman (2001) showed that framing effects are limited when the message source is perceived as untrustworthy, but sizable when the source is seen as credible. Moreover, it seems that "credibility exerts its strongest influence" (Hartman and Weber 2009: 540) when audiences are motivated to develop precise opinions or attitudes. The third and less explored dimension is the degree of identification with the source, which refers to the idea that the higher the degree of identification with the source, the more the given belief will be maintained.

Strictly with regard to source credibility, Priester and Petty (2003) suggest that when encountering a message from an untrustworthy source, people tend to be unsure whether the information is accurate or not. This incertitude makes people engage in a process of evaluation and elaboration in order to make sure that the received information is valid. On the other hand, when receiving messages from a trustworthy source, people tend to be confident that the information is accurate and accept the message without further questioning its validity. To put it differently, a message from a reliable source can have a more powerful impact compared to a message from an unreliable one (see also Tormala and Clarkson, 2007).

Transferring these theoretical research lines to framing effects studies, we expect that source credibility could play a role in moderating framing effects. More specifically, we expect that high credibility sources would enhance framing effects, whereas low credibility sources would limit these effects. Thus, we predict that:

Hypothesis 1a (H1a): If an individual is exposed to a message from a reliable source, framing effects are strong.

Hypothesis $1 b(H 1 b)$ : If an individual is exposed to a message from an unreliable source, framing effects are weak.

\section{b. The type of exposure}

Studies show that in real-life scenarios it is very likely for people to be exposed to different news frames at different moments. This means that, in the need to find conclusions that adhere to the "dynamics of day-to-day news use" (Lecheler and de Vreese 2013: 149), we should take into consideration that media present the information in frame flows. In this context, the work on persuasion studies developed by Zaller (1992) is essential because it explains how media effects are different according to the type of the message. The author states that media have a powerful effect on audiences only if they present messages repeatedly, in a consistent way. In contrast, he suggests that conflicting messages or those that 
are presented in a dissonant way do not have reckonable effects on audiences. That is why, applying these ideas to framing effects studies, frame flows can involve the repetition and the competition of news frame messages. Since the outcomes of these two are likely to vary, we will briefly explain the mechanisms that drive these different effects (also see Kahneman 2013; Entman 1993).

Repetitive exposure to news frames is an often addressed topic in the literature of framing effects (e.g., Cappella and Jamieson 1997; Nabi 2003; Price and Tewksbury 1997). Scholars argue that repetitive news framing leads to stronger effects on audiences since it results in higher levels of information accessibility. Once a message is constantly brought into people's minds, repetition functions as a factor that determines strong and stable attitude changes (see also Holland, Verplanken and Knippenberg 2003). Alongside accessibility, repetitive news messages are expected to generate constant levels of information applicability. Once a message is constantly available on the agenda, repetition favours the creation of new associations between certain considerations highlighted in the news and people's pre-existing thoughts (Price and Tewksbury 1997). In other words, if a framing effect has taken place, the repetitive exposure to that specific frame leads to higher levels of accessibility. In turn, they ease the connection between new (i.e., information in the news) and old (i.e., pre-existing considerations) issues (Matthes 2007). However, although repetitive exposure to news frames might lead to strong effects, they are limited by "individual evaluations of the quality of a frame" (Chong and Druckman 2007b: 651). Thus, heightened accessibility increases the probability of strong framing effects, but these effects depend on "how applicable a frame is to the individual in the first place" (Lecheler and de Vreese 2013: 150).

Competitive exposure has also received substantial attention in framing effects literature (e.g., Chong and Druckman 2007a, 2007b, 2008, 2010; Hansen 2007). The results indicate that people tend to reconsider their own beliefs when exposed to alternative interpretations. The exposure to competing or conflicting messages leads people to reconsider and weigh the information, which, in turn, causes minimal framing effects. However, the limited or even absent effect of competing messages on people's opinions, attitudes, and behaviours is related to the frame's strength (Chong and Druckman 2007b). When exposed to alternative messages, people tend to reject weak frames (i.e., frames that are easily forgotten or less applicable frames) and to be influenced only by strong frames (i.e., those frames that can be easily brought back into memory and are in accordance with people's pre-existing thoughts).

Thus, we expect that both repetitive and competitive messages could moderate framing effects on audiences' opinions, attitudes and behaviours. More specifically, we may assume that repetitive exposure to news frames could lead to stronger framing effects on audiences compared to the competitive kind. However, these expectations refer to the impact and magnitude of framing effects 
only in a short-term scenario (i.e., immediately after exposure). Yet, as stated from the beginning, we believe that only by taking more "naturalistic" approach to framing effects can we draw convincing conclusions about the real impact of media frames on people's attitudes. This is why we will further discuss the moderators of framing effects in a temporal context.

\section{Moderators of framing effects and their influence over time}

There are some studies that investigate either the role of source credibility or that of the type of exposure as moderators of framing effects, but we note that most research studies have drawn conclusions on observations of immediate framing effects. Hardly any studies use designs in which individuals are exposed and reexposed (i.e., at different time points) to different types of messages (i.e., repetitive versus competitive messages) from different sources (i.e., reliable versus unreliable sources). Following these lines, our view is that the effective impact of framing effect moderators on people's attitudes can be better understood by taking into account the influence of time.

Theoretical and empirical research studies on the duration of framing effects seem to follow two possible directions: One argues in favour of "fast running" framing effects (e.g., de Vreese 2004; Druckman and Nelson 2003), the other claims framing effects to be "long staying" (Lecheler and de Vreese 2011; Tewksbury et al. 2000). Those who see framing effects as transitory suggest that a period of two weeks from the initial exposure is enough to "mute" the effects. On the other hand, the supporters of lasting framing effects suggest that these effects can be seen even after a three-week period. However, few studies address the exact criteria for when framing effects can be considered lasting or transitory.

Regarding the influence of time on source credibility as a moderator of framing effects, we argue in favour of the idea that messages from constant reliable sources exert a stronger influence compared with messages from constant unreliable sources. Moreover, applying the classic work on sleeper effect, we expect that the latest source would have the most prominent impact, with more visible changes as time passes (Hovland, Janis and Kelley 1953; Hovland and Weiss 1951). According to the sleeper effect phenomenon, messages from reliable sources, as compared with messages from unreliable ones, have a greater impact at the beginning and a stable or even diminishing impact over time. One explanation could be that time seems to erase the differences in message source, but to enhance the impact of message content. In other words, this explains why messages from unreliable sources seem to have no initial impact, but an increasing one over time - people tend to forget the message source, but continue to be under the influence of message content. Thus, we expect that: 
Hypothesis $2 a(H 2 a)$ : If an individual is exposed to messages from constant reliable sources, initial framing effects on his or her attitudes will be stronger.

Hypothesis $2 b$ (H2b): If an individual is exposed to messages from constant unreliable sources, his or her attitudes remain stable.

Hypothesis $2 c(H 2 c)$ : If an individual is exposed to messages from different sources (reliable vs. unreliable), the latest source will have the most influence on people's attitudes.

Hypothesis 2d (H2d): The longer the period between two exposures, the greater the influence of the latest source (the first source, either reliable or unreliable, is forgotten).

Referring to the type of exposure and the role played by time, we argue in favour of the idea that repetitive exposures might function as framing effect intensifiers. As noted above, the power of repetitive messages depends on the rate of issue accessibility and applicability, which vary in line with the period of time since the last activation and according to the familiarity of the individuals with the repeated message (Feldman and Lynch 1988). Therefore, since previous exposures to political and economic topics are likely to be limited, we may assume that the longer the period between two exposures, the weaker the accumulative effect of repetition. To put it another way, we argue that repetitive exposures lead to strong framing effects, but the strength depends on the time elapsed between two successive exposures (see also Lecheler and de Vreese 2013). Thus, we predict that:

Hypothesis $3 a(\mathrm{H} 3 a)$ : If an individual is exposed to repetitive media messages over time, initial framing effects become stronger.

Hypothesis $3 b(\mathrm{H} 3 b)$ : The shorter the period between two exposures, the greater the influence of repetitive media coverage.

With respect to the role of competitive media messages, we argue in favour of the idea that competitive exposures lead individuals to reconsider their own beliefs, which results in rather insignificant framing effects. However, Chong and Druckman (2008) suggest that there is a tendency for people to activate the first and the last things from a list, as compared middle-placed ones. Applying this theory to framing effects, we may assume that the latest media exposure causes the most prominent effects on audiences' attitudes and behaviour. Therefore, considering this theory and the idea that accessibility tends to be lower as time passes, we expect that the latest media exposure has the strongest impact on people's attitudes, with even more powerful effects when the time between two successive exposures is longer. Specifically, we predict that: 
Hypothesis 3c (H3c): If an individual is exposed to competitive media messages, the latest message will play the most important role.

Hypothesis $3 d(H 3 d)$ : The longer the period between two exposures, the greater the influence of competitive media messages.

\section{Research methodology}

\section{a. Method}

In order to analyse the effects of source credibility and type of exposure over time, we conducted a survey experiment with three measurement time points among young people, namely students from a medium-sized university in Romania. As a stimulus material, we chose the issue of the present economic and political situation in Romania. We tested the impact of both message source and message coverage on people's political attitudes - specifically, political trust. The choice for the economic situation in Romania was motivated by the idea that, generally speaking, people tend to be interested in economic and political topics. Moreover, people tend to attach a higher level of importance to these topics compared to others, which guarantees the relevance of our study design.

This research study replicated a design developed by Lecheler and de Vreese (2013) and represents part of a more complex analysis which we developed. This is why some methodological lines discussed here are also parts of other similar studies (e.g., Buturoiu and Lupescu forthcoming; Corbu and Buturoiu 2015). Therefore, following some research lines developed by the two authors and specifically for the purpose of this study, we first established whether a news message source had a significant immediate effect on our dependent variable political trust. Second, we allocated our sample into subgroups, and traced the effects of both message source (reliable vs. unreliable) and type of exposure (repetitive vs. competitive) across two delayed measurement points.

\section{b. Design}

Initially, we randomly assigned participants to one of four conditions. These conditions were based on two alternative versions of a popular generic news frame, namely the "economic consequences" frame (Semetko and Valkenburg 2000) and two types of news frame sources - one reliable and one unreliable. Specifically, one frame suggested that the economic situation in Romania was positive, while the other one suggested the opposite. Their sources were, in turn, reliable and unreliable. Our choice for these alternative versions of both the economic frame and the type of source had two main advantages: it enabled us to create a scenario in which we could test both the impact of repetitive and competitive frames while ensuring commensurability across conditions (Lecheler 
and de Vreese 2013: 154). The external validity in our study was high, since both the positive and the negative economic frames coming from either reliable or unreliable sources are present in real media coverage in Romania today.

Our design also required participants to be assigned to a frame exposure scenario: repetitive exposure, competitive exposure, or single/no re-exposure. The participants in the single/no re-exposure group were used as a control group; they received only one frame at $\mathrm{T} 1$. In order to create a clean experimental design, each participant was tested at a maximum of two time points. This means that, after being tested immediately after news media exposure (T1), all the participants were split up into time groups and each participant was assigned to only one additional delayed measurement point: after one week (T2) or after one month (T3). This procedure left us with a total of 11 experimental conditions (see the Appendix). We ensured that each delayed time group contained a comparable number of participants for each condition. At the delayed measurement points, participants were interviewed on the basis of the same measures that were used in the immediate measurement test.

In order to create clean experimental conditions, we asked participants how much attention they had paid to news about the economic situation in Romania during the interim period $(1=$ no attention to $4=$ a great deal of attention). This measurement revealed that $77.5 \%$ of the participants $(\mathrm{N}=285)$ paid very little or no attention to this type of news. We also asked participants whether they had discussed the issue with someone else (for example with family or friends) during the interim period $(1=$ "I did not discuss it" to $4=$ "I discussed it a large number of times"). This measurement revealed that $84.2 \%$ of the participants discussed the issue hardly or not at all. These findings support the idea that the absence of the issue from people's personal agendas might have been a sign that their corresponding attitudes were fluid and open to influence by media, and support the further idea that the identified effects were due to experimental treatment only.

\section{c. Sample}

The participants in our study were 769 bachelors and masters Students from a medium-sized social sciences university in Romania. They were randomly chosen to participate in this study. For T1 they received a printed questionnaire $(\mathrm{N}=769)$, whereas for $\mathrm{T} 2$ and $\mathrm{T} 3$ they received an online questionnaire via Survey Monkey (T2 - N=151; T3 - N=134). The choice of students as participants in our study was motivated by the results of other research studies (e.g., O'Toole et al. 2003; Quintelier 2007), which suggest that younger citizens have less stable attitudes than older ones and may not be so politically sophisticated since they have less economic and political experience. Therefore, we expected that young 
people's attitudes would be particularly affected by both the message source and the type of media coverage (see also de Vreese and Elenbaas 2008).

\section{d. Procedure}

The experimental procedure consisted of three main steps for each participant. First, all participants received a printed questionnaire at time T1, containing one of the two possible alternative economic frames from one reliable and one unreliable source. Then, each participant was assigned to a re-exposure group: same message source/ different message source/ repetitive/ competitive/ single exposure. Thus, no participant was tested at more than two time points. Upon completing the questionnaire at T1, each participant was informed that he or she would be contacted for a follow-up study. The participants did not know that they would be asked the same questions again in this follow-up. The delayed news frame manipulations and the questionnaires were sent to participants after the respective time interval: one week or one month. Participants in the single exposure group did not receive an additional news frame. Following the delayed measurement, all participants were debriefed.

\section{e. Stimulus material}

The stimulus material consisted of one news article per condition at T1 and one additional news article at T2 and T3. Each news article contained one version of an economic consequences frame and indicated that the present economic situation in Romania was either good or bad. In addition, news articles contained one of two possible message sources - a reliable source versus unreliable source. Thus, articles varied with reference to their arguments and evaluative direction, as well as their message source. Specifically, we manipulated an article on economic and political issues in Romania, placing attention both on the economic situation itself and on the fact that politicians were responsible for Romania's economic situation.

The main reason for choosing an economic topic as a stimulus material in analysing people's political attitudes (political trust) was that, in general, people tend to blame politicians when the country's economic situation worsens. Intuitively, we might say that people blame those in power, mainly because power seems to nurture envy and discontent. In the aftermath of the global economic crisis, even without any available resources at hand, young people tended to feel a greater divide between the political elites and the population in general.

Given the design of the study, it was better to use constructed rather than actually published news materials, since the use of real news coverage could have minimized the commensurability across conditions (Lecheler and de Vreese 2013: 156). We chose an economic issue because it could be presented logically in terms 
of consequences. With respect to presentation, we adjusted the news articles as to be in line with the common layout and style of news coverage in Romanian newspapers. We kept the core information within each news article identical; meanwhile, some paragraphs in the story presented contrasting interpretations of Romania's present economic situation.

Regarding the message source, we chose to expose participants to both messages from reliable and unreliable sources. This choice was not only motivated by the study design itself, but also by the journalistic routine in Romania today, which presents news articles from either reliable or unreliable sources. As reliable sources, we chose analysts from the Financial Times (for news articles at T1) and analysts from Raiffeisen Bank (for news articles at T2 and T3). Our main motivation for choosing these sources was that both the Financial Times and Raiffeisen Bank are highly trustworthy entities on the international market. We expected that people would perceive these two message sources as authoritative ones. In contrast, as unreliable sources, we chose two Romanian public figures: Dorin Cocoş (for news articles at T1) and Emil Boc (for news articles at T2 and T3). The names of both are associated with controversial criminal cases from the last few years; thus, they are relevant examples of discredited sources.

Apparently different in nature - reliable message sources connected to institutions, and unreliable message sources connected to people - these sources were, however, expected to have similar moderator roles. We understood the Financial Times and Raiffeisen Bank to be reliable entities that are more important than the particular identities of their analysts. In contrast, we understood Dorin Cocoş and Emil Boc to be two unreliable entities who are well known in Romania and whose names are associated with corruption and controversy.

\section{f. Measures}

As explained above, source credibility was chosen as the independent variable in this research study. Since our aim was to determine and analyse the moderators of framing effects and their influence over time, we chose political attitudes specifically, political trust - as a dependent variable. The main reason for this choice was that, as studies suggest, media still have a significant influence on political attitudes (Cohen, Tsfati and Sheafer 2008; Stroud 2008). Political trust was measured with a scale adapted from Adriaansen, van Praag and de Vreese (2010: 452). There were seven items on a five-point scale, with higher scores indicating lower levels of political trust $(\mathrm{T} 1-\mathrm{N}=753: \mathrm{M}=3.91, \mathrm{SD}=0.56$, Cronbach's $\alpha=0.715$; T2 $-\mathrm{N}=151: \mathrm{M}=3.84$, SD $=0.65$, Cronbach's $\alpha=$ 0.831; T3 $-\mathrm{N}=134: \mathrm{M}=3.81, \mathrm{SD}=0.58$, Cronbach's $\alpha=0.767)$. For more details, see the Appendix. 


\section{Findings}

\section{a. The immediate impact of source credibility on political trust}

We expected that if an individual is exposed to a message from a reliable source, framing effects are strong. Similarly, we expected that if an individual is exposed to a message from an unreliable source, framing effects are weak. Therefore, we used an Independent Sample T Test in order to test the influence of the two types of message sources on our dependent variable, political trust. The results indicate that people exposed to a message from a reliable source have the same level of political trust as compared to those who did not receive any media message. This means that the exposure to messages from reliable sources does not lead to significant changes in people's political attitudes.

Regarding the moderating influence of unreliable sources, our findings show that people exposed to a message from an unreliable source tend to have a lower level of political trust as compared to those who were not exposed to media messages $(t(300)=-1.704, p<0.1)$. Although the significance is marginal, this means that exposure to a message from an unreliable source has an effect on people's political attitudes, in the sense that their level of political trust is lower. The same tendency can be seen when comparing the participants exposed to a message from a reliable source to those exposed to a message from an unreliable one. The exposure to a message from an unreliable source results in a statistically significant decrease in the level of political trust $(\mathrm{t}(303)=-2.095, \mathrm{p}<.05)$. In other words, exposure to messages from unreliable sources leads to significant framing effects on people's political attitudes.

The findings contradict our expectations, showing that messages from unreliable sources are more effective in creating stronger framing effects, and not vice versa. Thus, neither $\mathrm{H} 1 \mathrm{a}$, nor $\mathrm{H} 1 \mathrm{~b}$ can be supported. In other words, people tend to lose faith in politicians and politics (as an immediate effect) when confronted with media messages from discredited sources.

\section{b. The role of source credibility over time}

We predicted that if an individual is exposed to messages from constant reliable sources, initial framing effects on his or her attitudes will be stronger. Similarly, if an individual is exposed to messages from constant unreliable sources, his or her attitudes will remain stable. We used an Independent Sample $\mathrm{T}$ Test in order to test the influence of repeated exposure to these two types of message sources on our dependent variable, political trust. Our findings show that constant exposure to messages from reliable sources does not function as a multiplier of framing effects (i.e., we can see that levels of political trust among individuals do not increase after repeated exposure to messages from reliable sources). In contrast, consonant exposure to messages from unreliable sources causes a general decrease 
in the level of political trust $(\mathrm{t}(138)=1.688, \mathrm{p}<0.1)$. The same trend can be seen one month after the initial exposure $(\mathrm{t}(65)=1.681, \mathrm{p}<0.1)$. This means that our findings go against our predictions - the repeated exposure to messages from unreliable sources causes stronger effects on people's political trust, not vice versa. Thus, neither $\mathrm{H} 2 \mathrm{a}$, nor $\mathrm{H} 2 \mathrm{~b}$ can be supported.

We also predicted that the latest source will have the most significant influence on people's political attitudes. Moreover, we expected that the longer the period between two exposures, the greater the influence of the later source. We used an Independent Sample $\mathrm{T}$ Test in order to test the influence of alternative exposure to these two types of message sources on our dependent variable, political trust. Although they are not statistically significant, our findings show that the latest source could play a decisive role in influencing the level of political trust - the latest reliable source causes a higher level of political trust, as compared to the latest unreliable source, which causes a lower level of political trust. Moreover, our results show that those exposed to messages coming from consonant unreliable sources show a much lower level of political trust as compared to those who were first exposed to a message from an unreliable source, followed by one from a reliable source $(t(59)=-1.715, \mathrm{p}<0.1)$. The first unreliable source seems to have been forgotten.

Another important result is that time seems to function as a multiplier of framing effects - the latest reliable source determines a higher level of political trust, as compared to the latest unreliable source, which results in a visible decrease in the level of political trust (the mean difference between the levels of political trust for those exposed to a message whose latest source was reliable and those whose latest source was unreliable was 0.36). The difference was even bigger one month after the initial exposure - the latest reliable source led to a greater increase in the level of political trust, as compared to the latest unreliable source, which caused a more dramatic decrease in the level of political trust (for T3 - the mean difference between the levels of political trust for those exposed to a message whose latest source was reliable and those whose latest source was unreliable was 0.64 ). The problem here is that the results were not statistically significant due to the small number of cases. Thus, we conclude that both $\mathrm{H} 2 \mathrm{c}$ and $\mathrm{H} 2 \mathrm{~d}$ can be only partially supported.

\section{c. Repetitive media messages and their impact over time}

We expected that if an individual is exposed to repetitive media messages over time, initial framing effects become stronger. We also expected that the shorter the period between two exposures, the greater the influence of repetitive media coverage. Our findings show that repetitive media messages do not function as multipliers of framing effects over time and that shortening the period between 
two successive exposures does not strengthen framing effects on people's political attitudes. Thus, neither H3a, nor H3b can be supported.

\section{d. Competitive media messages and their impact over time}

We predicted that if an individual is exposed to competitive media messages, the latest message will have the most significant influence on people's political trust. We also predicted that the longer the period between two exposures (i.e., one month versus one week), the greater the influence of competitive media messages. We used an Independent Sample T Test in order to analyse the influence of the latest message on our dependent variable and to test the trend over time. The results indicate that, in general, the latest frame has the most significant influence on people's level of political trust. More specifically, those who were exposed to a negative followed by a positive message show a higher level of political trust, as compared to those who were first exposed to a positive and then to a negative message. Thus, we notice that the latest positive frame leads to a significantly higher level of political trust, as compared to the latest negative frame, which determines a decrease in the level of trust $(t(131)=2.658, \mathrm{p}<.01)$. Moreover, our findings show that, as time passes, the positive or negative influences of the latest frame on people's political attitudes become stronger. One month after the initial exposure, the latest positive frame determined a further increase in the level of political trust, as compared to the latest negative frame, which caused a further decrease in the level of political trust $(\mathrm{t}(64)=2.684, \mathrm{p}<.01)$. Thus, we may conclude that both $\mathrm{H} 3 \mathrm{c}$ and $\mathrm{H} 3 \mathrm{~d}$ can be supported.

\section{Discussion and ideas for future research}

Our research findings successfully show that both news source credibility and type of media exposure can moderate framing effects over time. More specifically, the data show that framing effects on people's political attitudes vary in their strength and direction according to moderator variables and to the passage of time. We believe that this study can be seen as a first step towards a more "naturalistic" approach in framing effects research. The "naturalistic" tone of this research was ensured through the fact that we both mimicked a real-life media scenario, integrating messages from reliable and unreliable sources with repetitive and competitive messages, and tested the duration of such framing effects.

The data from our analysis show that message source credibility, taken as an independent variable, moderates the immediate impact of a media message on people's political attitudes, taken as a dependent variable. Against our expectations, messages from unreliable sources seem to be more effective as compared to those from reliable ones. More specifically, the level of political trust is significantly lower after exposure to messages from unreliable sources. One 
possible explanation could be attributed to the fact that a message from an unreliable source (which is, in fact, a discredited political or business public figure) functions as a confirmation that the authorities are responsible for all social and political difficulties in general. This is why exposure to such messages causes a lower level of political trust. On the other hand, messages from reliable sources seem to function as "levellers" - they maintain framing effects at a stable or limited level. Surprisingly, we notice that, at least with respect to people's political attitudes, low credibility sources seem to enhance framing effects, whereas high credibility sources seem to limit these effects. As our results show, the level of political trust is, in general, at a rather low level (for T1, in the control group, $\mathrm{N}=147, \mathrm{M}=3.85, \mathrm{SD}=0.57$ ), which means that people tend to be sceptical towards the abilities and roles of politicians in society. In other words, it seems that, irrespective of the message source, people seem to be suspicious of the efficiency and attributions of political figures and tend to show a low level of political trust.

The immediate impact of source credibility as a moderator of framing effects seems to follow the same trend over time. Thus, we can conclude that repeated exposure to messages from unreliable sources functions as a multiplier of framing effects over time. As explained above, one possible reason for this result could be people's generally sceptical attitudes towards the authorities, namely figures who have either political or economic power. Following the trend, when confronted with repeated messages from unreliable sources (doubtful public figures), people tend to reconfirm their pre-existing attitudes - the increased scepticism towards political figures in general is even greater due to low-credibility sources; time seems to enhance the moderating role of source credibility, in the sense that people's level of political trust tends to decrease after exposure to one-monthdelayed messages from unreliable sources.

On the other hand, our research suggests that the latest source plays the most important role as a moderator of framing effects. This discovery is important since it offers a clue to the sleeper effect phenomenon ( Hovland, Janis and Kelley 1953; Hovland and Weiss 1951) - people seem to forget the first source of the message, but, as demonstrated by this study, they continue to be under the influence of the latest source. Thus, we may assume that, irrespective of its type (reliable versus unreliable), the latest message source will be decisive in moderating the impact of framing effects on people's political attitudes. Yet, this field remains open to further study, since our results are sometimes marginally significant, probably due to the low intensity of our stimulus material.

Referring to the type of exposure, we note that repetitive frames do not function in the sense of adding up effects; after repetitive media exposure, people's level of political trust remains stable. This result is in line with the idea that media could lead to strong effects through repetition, but that these effects are not necessarily cumulative (Corbu and Buturoiu 2015; Zaller 1992). On the 
other hand, the exposure to competitive frames seems to function as expected the latest media frame has the most significant influence on people's political attitudes, with more visible effects as time passes. Due to these findings, we may assume that other studies should consider the interplay between the first and last exposures. Since our results indicate that the last exposure is decisive and that media can have underlying effects, future studies should concentrate on the role of the first media message in the whole process (Corbu and Buturoiu 2015: 161).

There were, however, some limitations to this study. The most obvious one was that of the research method itself. Statistics show that experiments, as research methods, are useful for finding out whether and how people's attitudes and behaviours change due to different stimuli. However, we might assume that an experiment cannot completely reproduce real life. Second, we expected to discover some effects in line with some classical theories on mass-media's impact on people's opinions, attitudes and behaviours. However, such effects were not always found. For example, we expected messages from reliable sources to be more effective than those from unreliable ones, which did not prove to be true. Another limitation related to the salience of the framed issue and the complexity (or power) of the stimulus material (see McLeod and Reeves 1980: 30). As Gaines, Kuklinski and Quirk (2007: 6) suggest, the durability of framing effects depends on the issue "at stake"; we expected that young people would be particularly interested in economic issues, but our analysis showed, again, that this was not generally the case. In future studies, it would be interesting to use a different issue in order to see whether and how economic-related topics, as compared to other socially important ones, do really matter. In this context, another aspect that needs to be taken into consideration is the idea put forward by Shehata and Strömbäck (2013: 250) that suggests that when media repetitively present an issue (as in the case of economic topics) they might induce a kind of "chronic accessibility in the minds of the public". This "chronic accessibility" might, in turn, determine people to develop a feeling of habituation, which could lead to further discontent. Thus, news topics that present a good or bad economic situation as a result of political activities might feed more or less minor changes in people's political trust.

Another assumed limitation was that we exposed the participants in our study to a written news article, which could be regarded as somehow obsolete in the light of more or less recent technological developments. Our contention is that video-based stimuli material could have a more powerful impact; however, this remains open to future research. Thus, we consider that future research should take into account the idea that, sometimes, classical theories should be revisited and adapted to new technological environments, specifically because of the potential cultural differences between the settings in which such theories were created and those in which they are tested. 
Returning to the question of the title, we believe that our research successfully shows that source credibility is worth investigating and that it plays a very important role as a moderator of framing effects. We must note that, although sometimes our results did not follow our expectations, our analysis demonstrates that both the source credibility and the type of media exposure can play a role in moderating framing effects on people's political attitudes. Moreover, there is strong evidence that time functions as a multiplier of such framing effects. Thus, we believe this research study could be the first small step in a long tradition of future studies addressing framing effects theory from a more "naturalistic" perspective.

\section{Appendix}

\section{a. Experimental conditions}

1. Control group (without exposure to a news article)

2. Single exposure group 1 (news article from a reliable source + no re-exposure)

3. Single exposure group 2 (news article from an unreliable source + no re-exposure)

4. Same source 1 (news article from a reliable source + exposure to the same news article)

5. Same source 2 (news article from an unreliable source + exposure to the same news article)

6. Different source 1 (news article from a reliable source + news article from an unreliable source)

7. Different source 2 (news article from an unreliable source + news article from a reliable source)

8. Repetitive exposure 1 (positive news article + exposure to the same news article)

9. Repetitive exposure 2 (negative news article + exposure to the same news article)

10. Competitive exposure 1 (positive news article + negative news article)

11. Competitive exposure 2 (negative news article + positive news article).

\section{b. Dependent variable measurement-political trust scale}

Below are some statements reflecting people's opinion about politicians and the political system in Romania. For each statement, please indicate whether you agree or disagree (1 $=$ strongly disagree to $5=$ strongly agree):

- Politicians consciously promise more than they can deliver

- Ministers and junior-ministers are primarily self-interested

- To become a Member of Parliament, friends are more important than abilities

- Political parties are only interested in my vote, not in my opinion

- Politicians do not understand what matters to society

- Politicians are capable of solving important problems

- Most politicians are competent people who know what they are doing 


\section{References}

Adriaansen, Maud L., Philip van Praag and Claes H. de Vreese (2010): "Substance Matters: How News Content Can Reduce Political Cynicism." International Journal of Public Opinion Research 22(4): 433-457. DOI: 10.1093/ijpor/edq033

Adriaansen, Maud L., Philip van Praag and Claes H. de Vreese (2012): “A Mixed Report: The Effects of Strategic and Substantive News Content on Political Cynicism and Voting." Communications 37(2): 153-172.

Briñol, Pablo and Richard E. Petty (2004): "Thought Confidence as a Determinant of Persuasion: The Self-Validation Hypothesis." In: Geoffrey Haddock and Gregory R. Maio (eds.), Contemporary Perspectives on the Psychology of Attitudes. New York: Psychology Press.

Buturoiu, Raluca and Liliana Lupescu (forthcoming): "Minimal Effects or Not YET? Do Media Still Have a Role on Audiences' Political and Social Involvement?" Sfera Politicii.

Cappella, Joseph N. and Kathleen Hall Jamieson (1997): Spiral of Cynicism. The Press and the Public Good. New York: Oxford University Press.

Carter, Michael J. (2013): "The Hermeneutics of Frames and Framing: An Examination of the Media's Construction of Reality." SAGE Open April-June: 1-12.

Chong, Dennis and James N. Druckman (2007a): "A Theory of Framing and Opinion Formation in Competitive Elite Environments." Journal of Communication 57: 99-118. DOI: $10.1111 / \mathrm{j} .1460-2466.2006 .00331 . \mathrm{x}$

Chong, Dennis and James N. Druckman (2007b): "Framing Public Opinion in Competitive Democracies." American Political Science Review 101(4): 637-655. DOI: 10.1017/S0003055407070554

Chong, Dennis and James N. Druckman (2007c): "Framing Theory." Annual Review of Political Science 10: 103-126. DOI: 10.1146/annurev.polisci.10.072805.103054

Chong, Dennis and James N. Druckman (2008): "Dynamic Public Opinion: Framing Effects over Time." Presented at the Annual Meeting of the American Political Science Association, Boston: MA.

Chong, Dennis and James N. Druckman (2010): "Dynamic Public Opinion: Communication Effects over Time." American Political Science Review 104(4): 663-680. DOI: $10.1017 /$ S0003055410000493

Cohen, Jonathan, Yariv Tsfati and Tamir Sheafer (2008): "The Influence of Presumed Media Influence in Politics." Public Opinion Quarterly 72(2): 331-344. DOI: $10.1093 / \mathrm{poq} / \mathrm{nfn} 014$

Corbu, Nicoleta and Raluca Buturoiu (2015): "Repetitive and Competitive Media Frames and How They Affect Audiences' Trust." In: Redefining Community in Intercultural Context RCIC 15. Brașov: "Henri Coandă” Air Force Academy Publishing House.

De Vreese, Claes H. (2004): "The Effects of Strategic News on Political Cynicism, Issue Evaluations and Policy Support: A Two-Wave Experiment." Mass Communication \& Society 7: 191-214. DOI: 10.1207/s15327825mcs0702_4

De Vreese, Claes H., Hajo G. Boomgaarden and Holli A. Semetko (2011): "(In)direct Framing Effects: The Effects of News Media Faming on Public Support for Turkish Membership in the European Union." Communication Research 38(2): 179-205. DOI: $10.1177 / 0093650210384934$ 
De Vreese, Claes H. and Matthijs Elenbaas (2008): "Media in the Game of Politics: Effects of Strategic Metacoverage on Political Cynicism." Press/Politics 13(3): 285-309. DOI: $10.1177 / 1940161208319650$

Druckman, James N. (2001): "On the Limits of Framing Effects: Who Can Frame?" Journal of Politics 63: 1041-1066.

Druckman, James N. and Kjersten R. Nelson (2003): "Framing and Deliberation: How Citizens' Conversations Limit Elite Influence." American Journal of Political Science 47: 729-745. DOI: 10.1111/1540-5907.00051

Entman, Robert M. (1993): "Framing: Toward Clarification of a Fractured Paradigm." Journal of Communication 43(4): 51-58. DOI: 10.1111/j.1460-2466.1993.tb01304.x

Entman, Robert M., Jorg Matthes and Lynn Pellicano (2009): "Nature, Sources and Effects of News Framing." In: Karin Wahl-Jorgensen and Thomas Hanitzsch (eds.), The Handbook of Journalism Studies. Mahwah, NJ: Erlbaum.

Feldman, Jack M. and John G. Lynch (1988): "Self-Generated Validity and Other Effects of Measurement on Belief, Attitude, Intention and Behavior." Journal of Applied Psychology 73: 421-435. DOI: 10.1037/0021-9010.73.3.421

Gaines, Brian J., James H. Kuklinski and Paul J. Quirk (2007): "The Logic of the Survey Experiment Reexamined." Political Analysis 15(1): 1-20. DOI: 10.1093/pan/mpl008

Hansen, Kasper M. (2007): "The Sophisticated Public: The Effect of Competing Frames on Public Opinion." Scandinavian Political Studies 30(3): 377-396. DOI: 10.1111/j.14679477.2007.00185.x

Hartman, Todd K. and Christopher R. Weber (2009): "Who Said What? The Effects of Source Cues in Issue Frames." Political Behavior 31(4): 547-558. DOI: 10.1007/s11109009-9088-y

Holland, Rob W., Bas Verplanken and Ad van Knippenberg (2003): "From Repetition to Conviction: Attitude Accessibility as a Determinant of Attitude Certainty." Journal of Experimental Social Psychology 39: 594-601. DOI: 10.1016/S0022-1031(03)00038-6

Hovland, Carl I., Irving L. Janis and Harold H. Kelley (1953): Communication and Persuasion. New Haven: Yale University Press.

Hovland, Carl I. and Walter Weiss (1951): "The Influence of Source Credibility on Communication Effectiveness." Public Opinion Quarterly 15(4): 635-650. DOI: $10.1086 / 266350$

Iyengar, Shanto (1990): "Framing Responsibility for Political Issues: The Case of Poverty." Political Behavior 12(1): 19-40.

Iyengar, Shanto (1991): Is Anyone Responsible? How Television Frames Political Issues. Chicago: University of Chicago Press.

Kahneman, Daniel (2013): Thinking, Fast and Slow. New York: Farrar, Straus and Giroux.

Kohring, Matthias and Jorg Matthes (2007): "Trust in News Media." Communication Research 34(2): 231-252. DOI: 10.1177/0093650206298071

Kruglanski, Arie W., Ayelet Fishbach, Hans-Peter Erb, Antonio Pierro and Lucia Mannetti (2004): "The Parametric Unimodel as a Theory of Persuasion." In: Geoffrey Haddock and Gregory R. Maio (eds.), Contemporary Perspectives on the Psychology of Attitudes. New York: Psychology Press.

Lecheler, Sophie and Claes H. de Vreese (2011): "Getting Real: The Duration of Framing Effects." Journal of Communication 61(5): 959-983. DOI: 10.1111/j.14602466.2011.01580.x 
Lecheler, Sophie and Claes H. de Vreese (2013): "What a Difference a Day Makes? The Effects of Repetitive and Competitive News Framing Over Time." Communication Research 40(2): 147-175. DOI: 10.1177/0093650212470688

Lecheler, Sophie, Claes H. de Vreese and Rune Slothuus (2009): "Issue Importance as a Moderator of Framing Effects." Communication Research 36(3): 400-425. DOI: $10.1177 / 0093650209333028$

Lee, Nam-Jin, Douglas M. McLeod and Dhavan V. Shah (2008): "Framing Policy Debates. Issue Dualism, Journalistic Frames, and Opinions on Controversial Policy Issues." Communication Research 35(5): 695-718. DOI: 10.1177/0093650208321792

Marcus, George E., W.R. Neuman and Michael MacKuen (2000): Affective Intelligence and Political Judgment. USA: University of Chicago Press.

Marcus, George E., John L. Sullivan, Elizabeth Theiss-Morse and Daniel Stevens (2005): "The Emotional Foundation of Political Cognition: The Impact of Extrinsic Anxiety on the Formation of Political Tolerance Judgments." Political Psychology 26(6): 949-963. DOI: $10.1111 /$ j.1467-9221.2005.00452.x

Matthes, Jörg (2007): "Beyond Accessibility? Toward an On-line and Memory-Based Model of Framing Effects." Communications 32: 51-78. DOI: 10.1515/COMMUN.2007.003

Matthes, Jörg (2008): "Media Frames and Public Opinion: Exploring the Boundaries of Framing Effects in a Two-Wave Panel Study." Studies in Communication Sciences 8(2): 101128. DOI: $10.5167 /$ uzh-14296

Matthes, Jörg (2012): "Framing Politics: An Integrative Approach." American Behavioral Scientist 56(3): 247-259. DOI: 10.1177/0002764211426324

Matthes, Jörg and Christian Schemer (2012): "Diachronic Framing Effects in Competitive Opinion Environments." Political Communication 29: 319-339. DOI: 10.1080/10584609.2012.694985

McLeod, Jack M. and Byron Reeves (1980): "On the Nature of Mass Media Effects." In: Stephen B. Withey and Ronald P. Abeles (eds.), Television and Social Behavior: Beyond Violence and Children / A Report of the Committee on Television and Social Behavior, Social Science Research Council. New Jersey: Lawrence Erlbaum Associates.

Miller, Joanne M. and Jon A. Krosnick (2000): "News Media Impact on the Ingredients of Presidential Evaluations: Politically Knowledgeable Citizens Are Guided by a Trusted Source." American Journal of Political Science 44(2): 295-309. DOI: 10.2307/2669312

Nabi, Robin L. (2003): "Exploring the Framing Effects of Emotion." Communication Research 30(2): 224-247. DOI: 10.1177/0093650202250881

Nah, Seugahn and Deborah S. Chung (2011): "When Citizens Meet both Professional and Citizen Journalists: Social Trust, Media Credibility and Perceived Journalistic Roles among Online Community News Readers." Journalism 13(6): 714-730. DOI: $10.1177 / 1464884911431381$

Nelson, Thomas E., Zoe M. Oxley and Rosalee A. Clawson (1997): "Toward a Psychology of Framing Effects." Political Behavior 19(3): 221-246. DOI: 10.1023/A:1024834831093

O'Toole, Therese, Michael Lister, Dave Marsh, Su Jones and Alex McDonagh (2003): "Tuning out or left out? Participation and non-participation among young people." Contemporary Politics 9(1): 45-61. DOI: 10.1080/1356977032000072477 
Price, Vincent and David Tewksbury (1997): "News Values and Public Opinion: A Theoretical Account of Media Priming and Framing." In: George A. Barnett and Franklin J. Boster (eds.), Progress in Communication Sciences: Advances in Persuasion. Greenwich: Ablex Publishing Corporation.

Priester, Joseph R. and Richard E. Petty (2003): "The Influence of Spokesperson Trustworthiness on Message Elaboration, Attitude Strength, and Advertising Effectiveness." Journal of Consumer Psychology 13(4): 408-421. DOI: 10.1207/S15327663JCP1304_08

Quintelier, Ellen (2007): "Differences in political participation between young and old people. A representative study of the differences in political participation between young and old people." Presented at the Belgian-Dutch Politicologenetmaal, Belgium: Antwerp.

Schemer, Christian, Werner Wirth and Jörg Matthes (2012): "Value Resonance and Value Framing Effects on Voting Intentions in Direct-Democratic Campaigns." American Behavioral Scientist 56(3): 334-352. DOI: 10.1177/0002764211426329

Schuck, Andreas R. T. and Claes H. de Vreese (2006): "Between Risk and Opportunity News Framing and its Effects on Public Support for EU Enlargement." European Journal of Communication 21(5): 4-32. DOI: 10.1177/0267323106060987

Semetko, Holli A. and Patti M. Valkenburg (2000): "Framing European Politics: A Content Analysis of Press and Television News." Journal of Communication 50(2): 93109. DOI: $10.1111 / \mathrm{j} .1460-2466.2000 . t b 02843 . x$

Shehata, Adam and Jesper Strömbäck (2013): "Not (Yet) a New Era of Minimal Effects: A Study of Agenda Setting at the Aggregate and Individual Levels." The International Journal of Press/Politics 18(2): 234-255. DOI: 10.1177/1940161212473831

Smith, Colin Tucker, Jan De Houwer and Brian A. Nosek (2012): "Consider the Source:

Persuasion of Implicit Evaluations Is Moderated by Source Credibility." Personality and Social Psychology Bulletin 39(2): 193-205. DOI: 10.1177/0146167212472374

Stroud, Natalie Jomini (2008): "Media Use and Political Predispositions: Revisiting the Concept of Selective Exposure." Political Behavior 30(3): 341-366. DOI: 10.1007/s11109007-9050-9

Tewksbury, David, Jennifer Jones, Matthew W. Peske, Ashlea Raymond and William Vig (2000): "The Interaction of News and Advocate Frames: Manipulating Audience Perceptions of a Local Public Policy Issue." Journalism and Mass Communication Quarterly 77: 804-829. DOI: 10.1177/107769900007700406

Tormala, Zakary T. and Joshua J. Clarkson (2007): "Assimilation and Constrast in Persuasion: The Effects of Source Credibility in Multiple Message Situations." Personality and Social Psychology Bulletin 33(4): 559-571. DOI: 10.1177/0146167206296955

Tormala, Zakary T. and Richard E. Petty (2004): "Source Credibility and Attitude Certainty: A Metacognitive Analysis of Resistance to Persuasion." Journal of Consumer Psychology 14(4): 427-442. DOI: 10.1207/s15327663jcp1404_11

Xu, Qian (2013): "Social Recommendation, Source Credibility and Recency: Effects of News Cues in a Social Bookmarking Website." Journal \& Mass Communication Quarterly 90(4): 757-775. DOI: 10.1177/1077699013503158

Zaller, John R. (1992): The Nature and Origins of Mass Opinion. United Kingdom: Cambridge University Press. 